\title{
An information system for team work quality support: across the shop-floor and beyond
}

António Soares ${ }^{1}$, Waldemar Gaida ${ }^{2}$, Wolf Ritschel ${ }^{3}$, Christian Schmidt ${ }^{4}$

${ }^{I}$ INESC-UESP and University of Porto, R. José Falcão, 110, 4050 Porto, Portugal. Email: als@fe.up.pt

${ }^{2}$ WZL - RWTH Aachen, Steibachstraße, 53, D-52056 Aachen, Germany.Email:w.gaida@wzl.rwth-aachen.de

${ }^{3}$ University of Linköping, Dep. of Mechanical Engineering, $S$ 58183 Linköping, Sweden.Email: wolf@olivia.ikp.liu.se ${ }^{4}$ FIR, Aachen, Pontdriesch 1416 D-52062 Aachen, Germany Email:Sm@fir-main.fir.rwth-aachen.de

\begin{abstract}
This paper introduces the requirements for information systems supporting team work in manufacturing, under a Total Quality Management approach. The analysis and specification phases of a system in this category is described as well as the basic requirements for extending it beyond local shop-floors, towards networked enterprises.
\end{abstract}

Keywords

group work, self-management, CSCW, total quality management, information systems requirements specification 


\section{INTRODUCTION}

Many production enterprises today are restructuring towards flexible production by introducing so called manufacturing teams. Due to this development, there is increasing interest in the optimisation of these organisational forms quality performance, particularly in terms of cost of quality and continuous improvement. Thus, to support Total Quality Management (TQM) focused on manufacturing teams, effective and specific information systems (IS) must be developed. Furthermore, the need of an effective supply chain management and the requirements for joining complementary competencies, striving for an improved market response, extend the requirements for the IS team work support. This paper describes the analysis and specification development phases of an information system for team work support in manufacturing. This system, so-called ManTIS, addresses a set of basic and detailed requirements whose preconditions and elicitation process are outlined in the following sections.

\section{BASIC REQUIREMENTS FOR MANUFACTURING TEAMS I.S.}

The overall objective in ManTIS (ESPRIT project 22340, funded by the EU) was to establish effective support for manufacturing teams by developing a set of team performance tools. In addition to adopting Quality Management practices outlined by ISO 9000-9004, the objective was to develop a set of Quality Management Tools which are particularly tailored to support team structures on the shop floor.

\subsection{A vision for team work support in manufacturing under TQM}

Initially, Seven Team Performance Tools were considered covering: (1) Team Quality Monitoring, (2) Process Quality Monitoring, (3) Suggestion Book, (4) Self Assessment, (5) Team Communication, (6) Team Co-ordination and (7) Team Training, contributing for integrating quality, resources, people management and process aspects of work-groups and focusing on small and medium-sized enterprises (SMEs).

Team Quality Monitoring : Team quality monitoring tool is used for collecting and analysing performance data related to team aspects of production quality and volume, skills, empowerment and cross-functional teamwork. Reports can be made public within the company and can vary from standardised reports to ad-hoc queries.

Team Process Quality Monitoring : Process monitoring tools focus particularly on advanced quality aspects including statistical process control, cause-effect diagrams, and a knowledge base for unstructured or informal but relevant data of the Work Group. It encompasses all aspects of manufacturing where direct contact 
with production exists, including information about involved staff and departments, skills, costs, etc., derived from the actual situation.

Team Communication : Working together as a team requires fast and reliable exchange of all relevant information needed to do the job. ManTIS envisages the employment of multimedia and CSCW techniques to support relevant communication in teams as well as between teams. Bulletin boards and company news examples of services.

Team Co-ordination : This tool is based on functions for handling work-lists with sorting, grouping, and filtering facilities. It supports job rotation or changing of operations and work centres in the routing on an ad-hoc basis. It visualises links to jobs of other teams and enable the group to plan its flexible working hours.

Suggestion Book: Apart from performing basic production tasks, team members often have the knowledge and experience to recognise improvement potential for complex problems. In order to motivate team members to make problem solving suggestions, a fast and transparent suggestion management and reward system is required.

Self Assessment: A systematic method of continuous improvement involves the examination of manufacturing teams and help with the articulation of goals. The tool supports a team leader in the collection and analysis of information concerning quality, manufacturing processes, equipment, training, etc. Assessment data should not leave the team.

Team Training : Team training tool addresses a spectrum of skills that vary cross the employee groups. The tool displays information such as training programmes, training schedules, and even provide computer based training. The Team Training will allow people look for root causes rather then reacting to events.

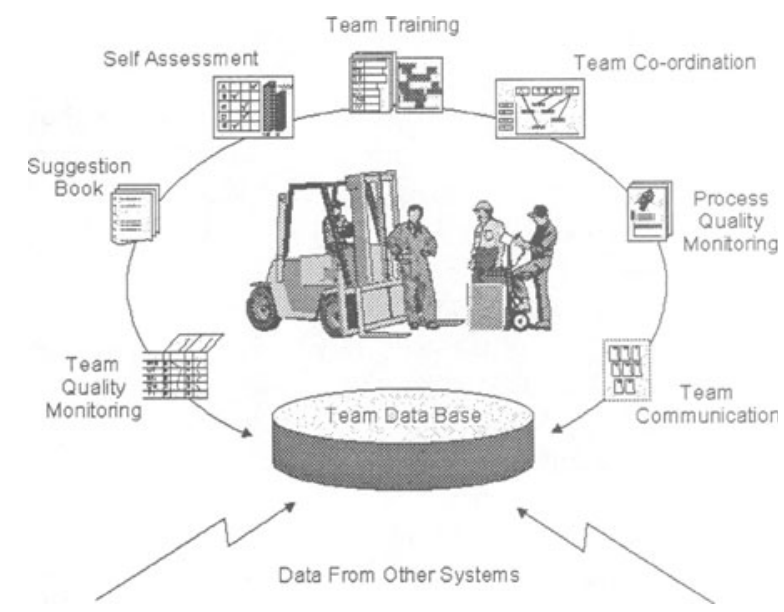

Figure 1 - The ManTIS tool set concept 


\subsection{Basic requirements for work group support}

Mandviwala and Olfman (1994) identify the generic requirements for work group information systems. In table 1 these requirements are enumerated and a short rationale for each one is given. Also, the relevance of these basic requirements in ManTIS design is stated.

Table 1 Basic requirements for ManTIS ( $c f$. Mandviwala and Olfman, 1994)

\begin{tabular}{|c|c|c|c|}
\hline \multicolumn{2}{|r|}{ Generic requirements } & Rationale & Relevance for ManTIS \\
\hline 1. & $\begin{array}{l}\text { Support of } \\
\text { multiple group } \\
\text { tasks }\end{array}$ & $\begin{array}{l}\text { groups may change their task } \\
\text { definition as to respond to } \\
\text { external and internal } \\
\text { requirements. }\end{array}$ & $\begin{array}{l}\text { Moderately relevant } \\
\text { As ManTIS scope is focused on the } \\
\text { quality activities, the multiplicity of } \\
\text { tasks is not big, but nevertheless the } \\
\text { range of quality tasks should be } \\
\text { carefully analysed }\end{array}$ \\
\hline 2. & $\begin{array}{l}\text { Support to } \\
\text { multiple work } \\
\text { methods }\end{array}$ & $\begin{array}{l}\text { tasks are completed using } \\
\text { appropriate work methods }\end{array}$ & $\begin{array}{l}\text { Moderately relevant } \\
\text { The majority of the ManTIS tools } \\
\text { will support tasks that can be } \\
\text { executed according various } \\
\text { methods }\end{array}$ \\
\hline 3. & $\begin{array}{l}\text { Support to the } \\
\text { development of } \\
\text { the group }\end{array}$ & groups need to grow & $\begin{array}{l}\text { Highly relevant } \\
\text { This is a central issue in ManTIS } \\
\text { because of the underlying } \\
\text { continuous improvement strategy }\end{array}$ \\
\hline 4. & $\begin{array}{l}\text { Provide } \\
\text { interchangeable } \\
\text { interaction } \\
\text { methods }\end{array}$ & $\begin{array}{l}\text { group communication is a } \\
\text { mixture of interaction } \\
\text { methods }\end{array}$ & $\begin{array}{l}\text { Moderately relevant } \\
\text { Tasks must be analysed in order to } \\
\text { derive the concrete interaction } \\
\text { patterns; they can be dependent on } \\
\text { group specific needs }\end{array}$ \\
\hline 5. & $\begin{array}{l}\text { Sustain multiple } \\
\text { behavioural } \\
\text { characteristics }\end{array}$ & $\begin{array}{l}\text { groups exhibit multiple } \\
\text { behaviours e.g., cohesion, } \\
\text { commitment, stress, } \\
\text { relations with the } \\
\text { organisation, use of time }\end{array}$ & $\begin{array}{l}\text { Moderately relevant } \\
\text { Should ManTIS impose tight } \\
\text { behaviours within the group (time } \\
\text { use, etc.)? }\end{array}$ \\
\hline 6. & $\begin{array}{l}\text { Accommodate } \\
\text { permeable } \\
\text { group } \\
\text { boundaries }\end{array}$ & $\begin{array}{l}\text { groups are coupled with the } \\
\text { rest of the organisation i.e., } \\
\text { they need to interact, share } \\
\text { information and work in } \\
\text { complementary projects } \\
\text { with other groups }\end{array}$ & $\begin{array}{l}\text { Highly relevant } \\
\text { The exchange of information and } \\
\text { the interaction with other groups / } \\
\text { departments is a crucial issue that } \\
\text { ManTIS should address }\end{array}$ \\
\hline 7. & $\begin{array}{l}\text { Adjustable to } \\
\text { the group's } \\
\text { context }\end{array}$ & $\begin{array}{l}\text { the system should be } \\
\text { "personizable" to individual } \\
\text { and overall group needs }\end{array}$ & $\begin{array}{l}\text { Highly relevant } \\
\text { Given the improbability of agreeing } \\
\text { on a unique group model, it is } \\
\text { mandatory the existence of } \\
\text { customisation facilities }\end{array}$ \\
\hline
\end{tabular}




\subsection{Team work effectiveness and the organisational context}

Until now, customer satisfaction has been the most important criteria in organisational effectiveness. Employee and group satisfaction is gaining importance and the "attractiveness" of the work place as well as social performance are likely to become future criteria (Kirsch, 1996). It was thus important to look at the contextual factors of group effectiveness in order to generate the requirements of ManTIS concerning its role in promoting the quality of working life, besides the primary improvement in the quality of products and processes. Three general aspects that are particularly important here:

Rewards and performance objectives. The reward system is a major influential factor of the group motivation and commitment. It must be congruent with the group work philosophy i.e., should be designed to recognise and reinforce the group performance. Reward systems for group work based on the management perceptions of individual performance, are likely to influence negatively the group cohesion and ultimately the efficiency and effectiveness. In the same way, performance objectives should be set up in collaboration with the group and the organisational control systems should monitor the performance of the group as a whole.

Training and technical consultation. In addition to an adequate group composition - concerning knowledge and skills - it is necessary a continuous learning process for skills enhancement. This process begins within the group itself and continues through training actions and technical and organisational consultancy. The establishment of organisational links between groups and personnel and technical departments are fundamental for technical, social and organisational consultation.

Task requirements and constraints. Management must clarify both the objective requirements of the group tasks and any constraints that may limit carrying out the work. For that, there must be a shared understanding of the company goals and how these relate to the specific ones of the working group. Only this way the group is able to plan adequately the performance of the tasks.

Besides the three basic factors above described, Pasmore (1989) add some others such as support in terms of resources, training and management commitment made available to the group to accomplish its purposes, the management of group membership, management of the relationships with the environment. We should also add the employment stability and the personnel recruitment policies, as two more important contextual factors in the group effectiveness.

\section{REQUIREMENTS ANALYSIS AND SYSTEM SPECIFICATION}

In order to analyse company's needs in terms of IS support to team work a two phase approach was employed. User input is regarded as critical for the 
development of methodologies and tools within a framework where the individual and the team are the key drivers of development. Thus, an in depth analysis of practices, problems and needs of manufacturing teams at different sites in Europe was performed based on the involvement of 3 industrial user groups from Portugal, Germany, Great Britain. The first phase included the completion of a questionnaire by the companies within the user groups and gave an outline of the current status and further expectations of the companies in terms of employee structure, employee involvement, teamwork features, products, manufacturing structure, quality culture and information technology support. These results were used afterwards to define subsets of companies for the second phase of the analysis. During the second phase, the organisational practices of the manufacturing teams in selected companies within the subset were analysed using structured interviews based on the EFQM (European Foundation for Quality Management) Model. The analysis gave an overview of the maturity of a sample of European companies in terms of team structures and TQM-Methods implementation on the shop floor. In Figure 2 the user requirements analysis procedure is outlined.

\subsection{First phase: global requirements identification and analysis}

\section{Questionnaire}

The goal of the questionnaire was to gather information about the current support of quality issues within manufacturing teams and about future expectations in this area. Furthermore, the analysis of the questionnaire replies was to identify and clarify the fundamental, organisational and human oriented requirements and structures in manufacturing. Therefore, a comprehensive set of questions covering all relevant topics concerning the tasks performed within a manufacturing team as well as its technical and organisational context was designed. In order to anticipate a representative rate of return, the questionnaire had also to be simple and compact. Industry specific references were avoided, in order to create a "one-sizefits-all" questionnaire permitting to analyse companies against one another within comparable sectors. The questionnaire covered the key areas of employee structure, employee participation, teamwork features, products, manufacturing structure, quality culture and information technology. It was sent to more than 700 companies in Portugal, England and Germany and were returned about $13 \%$.

\section{Results}

The survey covered a broad range of industrial sectors, all related with discrete production and where $75 \%$ of the surveyed companies had less than 200 employees. Approximately $60 \%$ of the companies had officially implemented a ISO9000 quality system implementation. Roughly, the $68 \%, 41 \%$ and $40 \%$ are skilled employees, respectively in Germany, Portugal and Great Britain. 


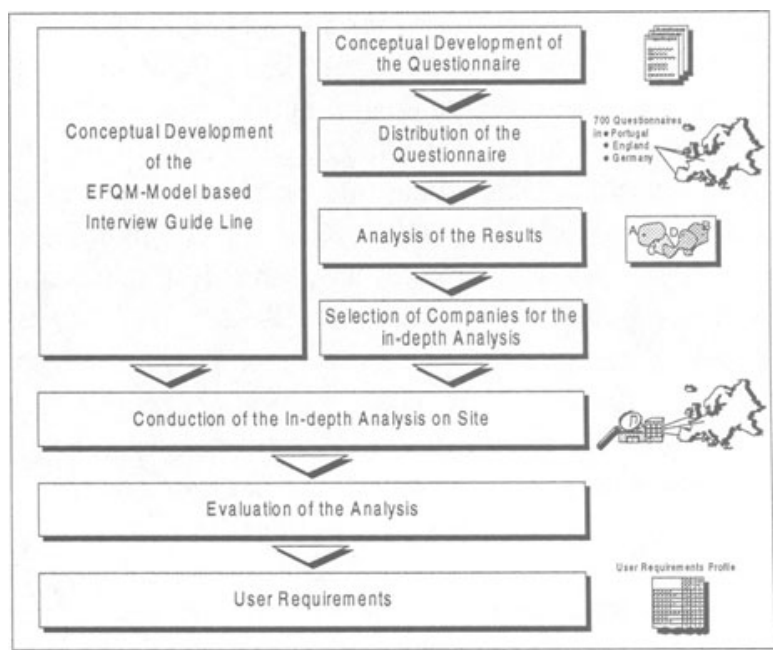

Figure 2 - User requirements elicitation process

Companies reporting a production organisation based on group work was about $12 \%$. Additionally to the actual state of companies with respect to quality and team implementation, a number of questions addressed the company's needs on these issues. This was measured by asking the companies to scale the need for support on team and quality aspects. A considerable gap between the actual situation and the desirable one was clear from this analysis, leading to the conclusion that there is a clear need for tools supporting and helping the transition. ManTIS will contribute to this by providing the adequate IT tools for team work under a TQM approach.

\subsection{Second phase: detailed requirements identification and analysis}

\section{The field work}

The conclusions of the first analysis phase led to the selection of companies within the above user group countries for an in depth analysis phase on site. The interview guideline for this on site detailed analysis was based on an extension of the EFQM model. This model suggests that the enablers for excellent enterprise results are (1) leadership, (2) policy \& strategy, (3) people management, (4) resources, and (5) processes (EFQM, 1996). These enablers affect (6) customer satisfaction, (7) people satisfaction, (8) impact on society and (9) business results. ManTIS addresses mainly (3) people management, (4) resources, and (5) processes as enablers, and (6) customer satisfaction and (9) business results as results. Using this model and regarding industrial practice, there are different ways to improve results. One way is to improve resources such as information resources, materials, equipment, technology, etc., for example through automation, new manufacturing methods, or application of new information technologies. Another area are the 
company's processes. Processes serve for production of goods or services and involve deployment of people and resources. The EFQM model criteria demand that key processes are identified, reviewed and if necessary revised to ensure continuous improvement of the organisation's activities. During this second phase, the organisational practices of manufacturing teams within a subset of companies were analysed using a model ( $\mathrm{EFQM})$ based interview guideline concerning the following key areas of interest: Organisation and Team Structure, Leadership, Policy and Strategy, People Management, Resources, Processes, Customer Satisfaction, People Satisfaction, Impact on Society and Business Results. The detailed interview workshops were conducted at 11 companies in the three countries during a 2-3 day on site visit. Management representatives as well as shop floor employees were involved in the interview workshops. To avoid that the management points of view could bias the results, the workshops were separated into a management and a shop floor part. This approach permitted to look at the companies quality politics and culture and to obtain information about how this quality politic is recognised and accepted within the Manufacturing Team.

\section{Data analysis and results}

Based on the interviews data, the initial concept of the Seven Team Performance Tools as described before was reviewed. For this review, a QFD (Quality Function Deployment) Matrix approach was applied, being the 66 criteria of the detailed analysis together with weighting factors for each criterion correlated with the Seven Team Performance Tools. For each issue the ManTIS team discussed whether this issue was addressed by the Team Performance Tools. After completing the QFD-Matrix, the scope and the weight of each of the tools could be defined by analysing the columns of the QFD-Matrix tool by tool, giving an implicit definition of each of the Team Performance Tools and their scope. Analysing the columns of the QFD-Matrix tool by tool, this gives an implicit definition of each of the Team Performance Tools and their scope.

In order to obtain a comprehensive user requirement profile, the collected data and information had to be analysed and evaluated in a structured and systematic way. The underlying approach conducting the evaluation is related to the concept applied in the model based interview guideline. For each question in the guideline the level of importance, the approach related to the achieved results, the grade of deployment related to the scope and the potential benefits for IT-support were weighed within an answer rating scheme. This scale distinguishes the specific relevance from $0 \%$ to $100 \%$.

The overall result of the review of the Seven Team Performance Tools is that all of these Tools are needed to satisfy stated user requirements. The Process Quality Monitoring Tool (30\%), Team Communication Tool (21\%), Team Co-ordination Tool (19\%) and Team Quality Monitoring Tool (14\%) have the highest score followed by the Team Training Tool (8\%), Self Assessment Tool (5\%), and the Suggestion Book Tool (3\%). 


\section{Preliminary system requirements specification}

Analysing the columns of the QFD-Matrix tool by tool gives an implicit definition of each of the Team Performance Tools and their scope. Table 2 summarises this analysis, providing a preliminary specification of the system.

\section{Table 2}

\begin{tabular}{|c|c|c|}
\hline Tool & Input (other systems) & Processing \\
\hline $\begin{array}{l}\text { Process Quality } \\
\text { Monitoring }\end{array}$ & $\begin{array}{l}\text { Basic SPC data, MRP, } \\
\text { process data, other } \\
\text { methods and tools, } \\
\text { customer feedback } \\
\text { data, feedback from } \\
\text { management, company } \\
\text { goals. }\end{array}$ & $\begin{array}{l}\text { Local input: targets/goals set by the team, } \\
\text { identification of processes, process changes, } \\
\text { evaluation of process changes, preventive } \\
\text { action, non-conformities, corrective action, } \\
\text { process improvement plans, inspection and test } \\
\text { results } \\
\text { Processing: decision support, application of } \\
\text { methods and tools, cost and performance } \\
\text { computation, computation of trends in quality. } \\
\text { Local output: displaying data, productivity and } \\
\text { operating efficiency, maintenance of local data } \\
\text { base. }\end{array}$ \\
\hline $\begin{array}{l}\text { Team } \\
\text { Communication }\end{array}$ & $\begin{array}{l}\text { Assistance from } \\
\text { management, process } \\
\text { improvement plans, } \\
\text { policy and strategy, } \\
\text { various technical } \\
\text { documents, quality } \\
\text { procedures, } \\
\text { instructions, informal } \\
\text { messages, company } \\
\text { news. }\end{array}$ & $\begin{array}{l}\text { Local input: responsibility, authority and } \\
\text { interrelation of personnel, statements of targets, } \\
\text { reporting of non-conforming product } \\
\text { Processing: distribution, receiving and storing } \\
\text { of data. } \\
\text { Local output: displaying data, maintenance of } \\
\text { local data base. }\end{array}$ \\
\hline $\begin{array}{l}\text { Team Co- } \\
\text { ordination }\end{array}$ & $\begin{array}{l}\text { MRP, shop orders; } \\
\text { inspection, measuring } \\
\text { and test equipment } \\
\text { data. }\end{array}$ & $\begin{array}{l}\text { Local input: changes of shop orders, resource } \\
\text { requirements, exchange of resources data, } \\
\text { feasibility data, purchase orders, marshalling } \\
\text { data, verification of job set-ups, identification of } \\
\text { products, incoming goods inspection; control, } \\
\text { calibration and maintenance of inspection, } \\
\text { measuring and test equipment. } \\
\text { Processing: filtering, work lists provision, } \\
\text { support of feasibility and cost checks. } \\
\text { Local output: displaying data, maintenance of } \\
\text { local data base. }\end{array}$ \\
\hline
\end{tabular}




\begin{tabular}{|c|c|c|}
\hline $\begin{array}{l}\text { Team Quality } \\
\text { Monitoring }\end{array}$ & $\begin{array}{l}\text { Feedback from } \\
\text { management, other } \\
\text { methods and tools, } \\
\text { targets/goals. }\end{array}$ & $\begin{array}{l}\text { Local input: improvement plans, targets and } \\
\text { goals, employee data, people satisfaction, } \\
\text { corrective and preventive action. } \\
\text { Processing: displaying data, support for people } \\
\text { resource planning, team success } \\
\text { Local output: displaying data, maintenance of } \\
\text { local database. }\end{array}$ \\
\hline Team Training & $\begin{array}{l}\text { Training material } \\
\text { (multimedia, computer } \\
\text { based training) }\end{array}$ & $\begin{array}{l}\text { Local input: training need, editing the training } \\
\text { plan. } \\
\text { Processing: multimedia viewer, training } \\
\text { program support. } \\
\text { Local output: displaying data, maintenance of } \\
\text { local database. }\end{array}$ \\
\hline Self Assessment & $\begin{array}{l}\text { Targets, goals; process } \\
\text { data. }\end{array}$ & $\begin{array}{l}\text { Local input: assessment data } \\
\text { Processing: processing of assessment data } \\
\text { (statistics, etc.) } \\
\text { Local output: displaying data, maintenance of } \\
\text { local data base. }\end{array}$ \\
\hline $\begin{array}{l}\text { Suggestion } \\
\text { Book }\end{array}$ & None & $\begin{array}{l}\text { Local input: suggestions, complaints. } \\
\text { Processing: tracing of suggestions and } \\
\text { complaints, statistics. } \\
\text { Local output: displaying data, maintenance of } \\
\text { local data base }\end{array}$ \\
\hline
\end{tabular}

Local output of ManTIS tools is made available to other systems according to a publishing-subscribing scheme.

\section{BEYOND SHOP-FLOOR COOPERATION: BASIC REQUIREMENTS}

Close co-operation between manufacturing companies, namely the SME's, is nowadays an emerging need and will be a critical competitive factor in the next decade. The needs of an effective supply chain management and the requirements for joining complementary competencies, striving for an improved market response, lead to two main forms of enterprises' co-operation at the manufacturing level: supply-chain co-operation and technical co-operation networks. Although exemplars of the two forms can be found throughout Europe, the full potential of these approaches is still latent, at least in some member states. Turning the attention to the supply chain management, it is widely accepted that these commercially linked SME's should also develop long term relationships not only with the major clients but also within each other in order to strengthen their technical and negotiation basis. Therefore, there is a need for developing 'European' responses to global supply chain phenomena which leads from one side to establishing and developing collaborative networks of SME's in technical 
matters such as product development and quality management, and to the creation of quick logistics management links for improving the global response of the supply chain to unavoidable plans deviations. It seems thus "natural" the extension of the internal customer/supplier approach (in which ManTIS was based) to the supply-chain management by creating the conditions for direct links between groups at different companies and enabling their close collaboration in a range of planning and control issues, problem solving, technical and quality advising, etc.. The generic requirements for this system are:

\section{Inter-teams direct supply chain management}

- to provide information on the team supply dependencies, continuously updated, using intuitive graphic and browsing interfaces; examples of such information is the depicting of the network of suppliers and customers for the fulfilment of an upcoming manufacturing order, the foreseeable due dates of expected components as declared by the supplying teams in the supplying companies, or the clients required delivery dates for the current and upcoming orders,

- to provide team-to-team direct early warnings, bypassing the normal procedures of the companies' logistics management systems, e.g., the forwarding of a warning message throughout the supply chain when one of the supplying teams is not able to fulfil a due date,

- to support team-to-team negotiation for the re-planning of deliveries

- to maintain the consistency with the companies' logistics management systems

\section{Inter-teams technical co-operation}

- to support team-to-team negotiation regarding the fine tuning of component/sub-product deliveries,

- to support the exchange of relevant technical information regarding the product components manufacturing,

- to support the exchange of quality related information, e.g., the explanation of the of the quality requirements for the components in the upcoming orders,

\section{Continuous improvement network}

The system will provide an infrastructure for the sharing of continuous improvement experiences and a range of training materials made available electronically by each working group. The account of the manufacturing team performance over a medium term period, the reasons for specific improvement actions, the analysis of failures modes and quality problems, are examples of findings and experiences that the manufacturing teams at each company can make available to the other groups participating in the supply chain. The system will enable global searches on selected topics through the network of databases. 


\section{REFERENCES}

European Quality Award (1996), Application Brochure; European Foundation for Quality Management (EFQM), Brussels Representative Office, Avenue des Pleiades 19, 1200 Brussels, Belgium.

House, J. (1981), Work Stress and Social Support, Addison-Wesley, Reading MA. Kirsch, C., Nagamichi, M., 1996, Cross-cultural comparison of Advanced Manufacturing Systems: The Group Work Paradigm, Manufacturing Agility and Hybrid Automation-I, Koubek \& Karwowski (Eds.), IEA Press.

Mandviwalla, M., Olfman, L. (1994), What Do Groups Need? A Proposed Set of Generic Groupware Requirements, ACM Transactions on Computer-Human Interaction, Vol. 1 No. 3, September, pp. 245-268.

Pasmore, W., 1988, Designing Effective Organizations - The Socio-Technical Systems Perspective, John Wiley \& Sons, Inc.

\section{BIOGRAPHY}

António Soares has a Ph.D. in Electrical and Computers Engineering. He is an Assistant Professor at the Faculty of Engineering of the University of Porto and senior researcher at INESC. His main research interests are the social and organisational aspects of information systems development in manufacturing enterprises.

Dipl.-Ing. Waldemar Gaida studied Mechanical Engineering at the Aachen University of Technology. Since 1996 he is leading the Quality Management Group of the Chair of Metrology and Quality Management directed by Prof. Dr. T. Pfeifer.

Wolf Ritschel has a Ph.D. in Mechanical Engineering (Quality Technology) from Aachen University of Technology, Germany. He is an Assistant Professor at the Division of Industrial Ergonomics, Linköping University, Sweden.

Dipl.-Ing. Christian Schmidt is research engineer at the FIR - Research Institute for Operations Management - in Aachen since 1996. His range of activities covers the reengineering of technical order processing, the selection and implementation of ERP-Systems and the design of environmental and quality management systems. 